\title{
NITROGÊNIO FOLIAR COMPLEMENTAR E DIFERENTES POPULAÇÕES DE PLANTAS NA CULTURA DO MILHO
}

\author{
FABIANO PACENTCHUK ${ }^{1}$, JAQUELINE HUZAR NOVAKOWISKI ${ }^{2}$, \\ BRUNO SBARDELOTTO DEPARIS ${ }^{1}$, CRIZ RENE ZANOVELLO ${ }^{1}$, FELIPE POZZAN ${ }^{3}$ \\ e ITACIR ELOI SANDINI ${ }^{1}$
}

${ }^{1}$ Universidade Estadual do Centro-Oeste, fabianopacentchuk@gmail.com, bruno_deparis_22@hotmail.com,renecriz@hotmail.comeisandini@hotmail.com. ${ }^{2}$ Universidade de Passo Fundo-UPF, jaquehuzar@gmail.com.

${ }^{3}$ Instituto Federal do Triangulo Mineiro-Campus Uberaba,felipe.pozzan@agrichem.com.br .

Revista Brasileira de Milho e Sorgo, v.18, n.2, p. 269-280, 2019

\begin{abstract}
RESUMO - O uso do $\mathrm{N}$ complementar é uma alternativa importante para o fornecimento de $\mathrm{N}$ para cultura do milho e resulta em acréscimo de produtividade. Entretanto, estudos que demonstrem a relação entre aplicação de $\mathrm{N}$ complementar e a população de plantas são escassos. O propósito deste trabalho foi estudar como a aplicação de $\mathrm{N}$ complementar em diferentes populações de plantas influencia a produtividade e os componentes de rendimento da cultura do milho. O experimento foi conduzido em DBC em esquema fatorial 2 x 4 × 5, com quatro repetições, sendo: duas safras (2014/15 e 2015/16), quatro populações de plantas (55.000, 70.000, 85.000 e 100.000 plantas ha $\left.{ }^{-1}\right)$ e cinco doses de $\mathrm{N}$ complementar $\left(0,5,10,15\right.$ e $\left.20 \mathrm{~kg} \mathrm{ha}^{-1} \mathrm{de} \mathrm{N}\right)$. Houve diferença entre as safras para todas as variáveis estudadas. A aplicação de até $10,60 \mathrm{~L} \mathrm{ha}^{-1}$ de $\mathrm{N}$ complementar apresentou acréscimo de produtividade de $722 \mathrm{~kg} \mathrm{ha}^{-1}$. $\mathrm{O}$ aumento da população de plantas proporcionou aumento de produtividade, da altura de inserção da primeira espiga e diminuição da MMG, do número de grãos/fileira e grãos/espiga. Não houve interação entre população de plantas e N complementar, sugerindo que o efeito positivo do $\mathrm{N}$ complementar é independente da população de plantas.
\end{abstract}

Palavras-chave: arranjo de plantas, nitrogênio via foliar, Zea mays L.

\section{COMPLEMENTARY NITROGEN APPLICATION IN DIFFERENT PLANT POPULATIONS OF MAIZE CROP}

\begin{abstract}
The use of complementary nitrogen is an important alternative for the supply of $\mathrm{N}$ for maize crop and results in increased yield. However, studies demonstrating the relationship between complementary $\mathrm{N}$ application and plant population are scarce. The purpose of this work was to study how the application of complementary $\mathrm{N}$ in different plant populations influences the yield and yield components of the maize crop. The study was conducted in RBD in a 2 x 4 x 5 factorial scheme with four replications, being: two crops seasons (2014/15 and 2015/16), four plant populations $\left(55,000,70,000,85,000\right.$ and 100,000 plants ha $\left.{ }^{-1}\right)$ and five doses of complementary $\mathrm{N}(0,5,10,15$ and 20 $\mathrm{kg} \mathrm{ha}^{-1}$ of $\mathrm{N}$ ). There was difference between the crop seasons for all variables studied. The application of up to $10.60 \mathrm{~L}$ $\mathrm{ha}^{-1}$ of complementary $\mathrm{N}$ increased yield in $722 \mathrm{~kg} \mathrm{ha}^{-1}$. The increase of plant population increased yield and height of insertion of the first ear and decreased TGW, number of grains/row and grains/ear. There was no interaction between plant population and complementary $\mathrm{N}$, indicating that the positive effect of complementary $\mathrm{N}$ in yield is independent of the plant population.
\end{abstract}

Keywords: Plant arrangement, foliar nitrogen, Zea mays L. 
A crescente demanda mundial por alimentos e seus derivados torna o cultivo do milho (Zea mays L.) alvo de diversos estudos visando a obtenção de elevados níveis de produtividade da cultura (Chagas et al., 2018). É importante salientar que a produtividade da cultura do milho é uma variável complexa e depende da interação entre fatores genéticos, ambientais e de manejo (Kappes et al., 2011).

Dentre as variáveis que podem interferir na produtividade da cultura, destaca-se a população de plantas. Segundo Primaz et al. (2015), o aumento da produtividade pode ser explicado pelo ajuste da densidade de plantas, pois com o aumento da densidade de semeadura o rendimento por planta é menor, porém, a produtividade por área é maior.

A densidade e o arranjo de plantas têm grande importância na captação e na eficiência de conversão da radiação fotossinteticamente ativa interceptada pelo dossel à produtividade de grãos (Takasu et al., 2014). A utilização do melhor arranjo populacional incrementa o rendimento de grãos da cultura do milho, uma vez que aperfeiçoa a interceptação da radiação solar pelas plantas (Vitorazzi et al., 2017).

Em estudo realizado por Lana et al. (2014), foi verificado que a utilização de uma densidade de semeadura de 80.000 plantas ha-1 em comparação à

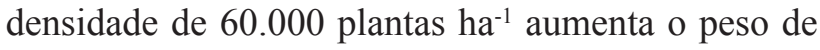
mil grãos, o que consequentemente afetará a produtividade da cultura.

Como evidenciado anteriormente, a densidade de plantas de milho, quando bem manejada, pode afetar positivamente a produtividade da cultura, entretanto, o aumento no número de plantas por área pode acarretar também mudanças nos componentes de rendimento da cultura (Farinelli \& Cerveira Júnior, 2014).

Neste contexto, o aumento na população de plantas aumentará também a competição por recur- sos de produção, como os nutrientes. Sabe-se que o fornecimento adequado de nutrientes, via de regra, proporciona aumentos significativos de produtividade nas culturas, e dentre os nutrientes que são necessários para obtenção de elevadas produtividades se destaca o nitrogênio (Cancellier et al., 2011).

$\mathrm{O} \mathrm{N}$ está ligado diretamente ao crescimento e desenvolvimento das plantas, é componente essencial da molécula de clorofila, constituinte de proteínas, enzimas, coenzimas, ácidos nucleicos e citocromos, atua diretamente no processo de divisão e expansão celular (Novakowiski et al., 2011).

A principal fonte de $\mathrm{N}$ para a cultura do milho é a ureia. No entanto, a ureia possui elevada suscetibilidade à volatilização de amônia $\left(\mathrm{NH}_{3}\right)$, um tipo de perda que é mais intensificado em países de regiões tropicais, como o Brasil, onde há predomínio de altas temperaturas na maior parte do ano (Frazão et al., 2014).

Uma alternativa para aumentar a eficiência da adubação nitrogenada seria a complementação com nitrogênio foliar. De acordo com Taiz et al. (2017), a maioria das das espécies vegetais, inclusive a cultura do milho, consegue absorver nutrientes minerais aplicados nas folhas por aspersão. Desta forma, a complementação pode aperfeiçoar o sistema produtivo e contribuir para a obtenção de resultados mais satisfatórios.

É sabido que a cultura do milho é responsiva ao acréscimo de população com interação da adubação nitrogenada em cobertura em anos de clima favorável (Folador et al., 2014). Todavia, estudos com o objetivo de entender a relação entre o uso de $\mathrm{N}$ complementar e diferentes populações de plantas em híbridos de milho modernos são inexistentes.

Desta maneira, o propósito deste trabalho foi estudar como a aplicação de $\mathrm{N}$ complementar em diferentes densidades populacionais de plantas influen- 
ciam a produtividade e os componentes de rendimento da cultura do milho.

\section{Material e Métodos}

O experimento foi realizado no município de Candói-PR, na Fazenda Modelo, nas safras 2014/15 e 2015/16. O município está situado na região Centro-Sul do Estado do Paraná, nas coordenadas geo-

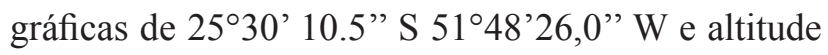
de aproximadamente $1.100 \mathrm{~m}$. O clima da região é classificado segundo Köppen (Maak, 1968) como $\mathrm{Cfb}$ (subtropical mesotérmico úmido sem estações secas e com verões amenos), com precipitação média anual de $1.944 \mathrm{~mm}$, média anual de temperatura mínimas de $12,7^{\circ} \mathrm{C}$, e média anual de temperaturas máximas de $23,5^{\circ} \mathrm{C}$ (Figura 1). Os dados foram coletados na estação meteorológica do IAPAR, localizada no campus Cedeteg, UNICENTRO. O solo da área experimental é do tipo Latossolo Bruno Distroférrico Típico (Santos et al., 2013b).

Foi utilizado o delineamento de blocos ao acaso em arranjo fatorial de $2 \times 4 \times 5$, com quatro repetições, sendo duas safras agrícolas (2014/15 e 2015/16); quatro populações de plantas $(55.000,70.000,85.000$ e 100.000 plantas ha $\left.^{-1}\right)$ e cinco doses de nitrogênio complementar $\left(0,5,10,15\right.$ e $\left.20 \mathrm{~L} \mathrm{ha}^{-1} \mathrm{~N}\right)$ aplicado via foliar. A unidade experimental foi constituída de sete linhas com espaçamento de $0,40 \mathrm{~m}$ e comprimento de 6,0 m (Tabela 1). Em ambas as safras, o experimento foi implantado em sistema plantio direto sobre palhada de aveia-preta. A escolha do híbrido utilizado (Tabela 1) seguiu o critério de representatividade da região, ou seja, o híbrido com maior área semeada naquela determinada safra.

Foram aplicados $200 \mathrm{~kg} \mathrm{ha}^{-1}$ de $\mathrm{N}$ em cobertura, em aplicação parcelada em V2 e V4 (Tabela 1). As doses de $\mathrm{N}$ complementar foram aplicadas no es-

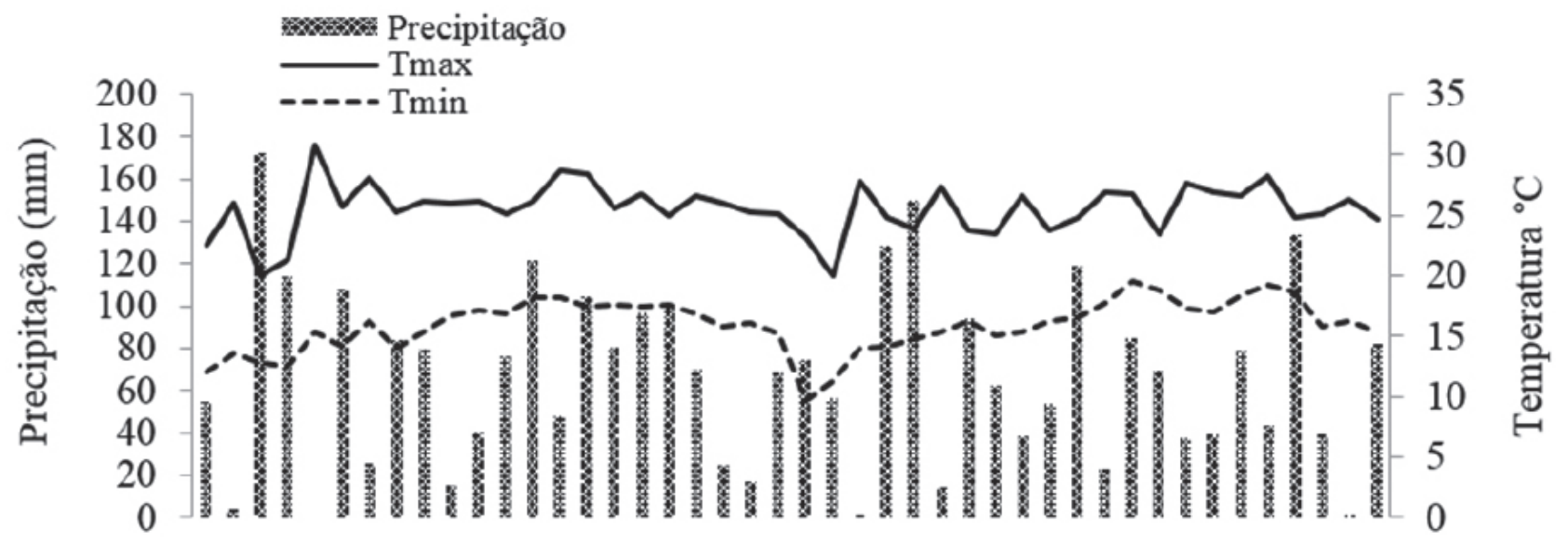

Sep Out Nov Dez Jan Fev Mar Abr Sep Out Nov Dez Jan Fev Mar Abr

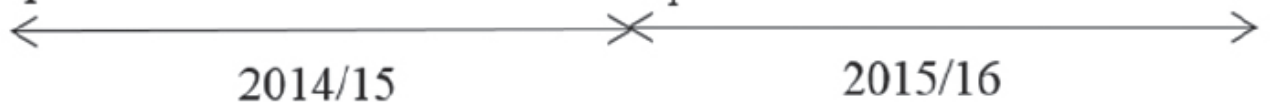

Figura 1. Valores médios das temperaturas máximas $\left(\operatorname{Tmax}-{ }^{\circ} \mathrm{C}\right)$ e mínimas $\left(\operatorname{Tmin}{ }^{\circ} \mathrm{C}\right)$ e precipitação pluviométrica (mm) no período de condução dos experimentos. Guarapuava-PR, 2018. 
tádio VT e com pulverizador costal elétrico de pressão constante, utilizando uma estrutura de metal para simular a aplicação aérea. Foram utilizadas pontas de pulverização de jato leque XR 110:02, espaçadas em $50 \mathrm{~cm}$, resultando num volume de calda de $160 \mathrm{~L} \mathrm{ha}^{-1}$. A fonte de $\mathrm{N}$ complementar utilizada foi o produto comercial Nitamin ${ }^{\circledR}$, que é composto por $33 \%$ de N.

As variáveis avaliadas foram: produtividade $\left(\mathrm{kg} \mathrm{ha}^{-1}\right)$, massa de mil grãos (MMG - g), porcentagem de grãos ardidos (\%), altura de inserção da espiga $(\mathrm{cm})$, altura de planta $(\mathrm{cm})$, número de fileiras por espiga, número de grãos por fileira e número de grãos por espiga.

Antes da colheita, com o auxílio de uma régua graduada, realizaram-se as medições de altura de inserção da primeira espiga e altura final de planta. Para isso, foram medidas três plantas escolhidas aleatoriamente na área útil de cada parcela. A área útil da parcela foi de $10 \mathrm{~m}^{2}$.

Para produtividade, colheram-se as espigas de duas linhas da área útil da parcela. Posteriormente as espigas foram trilhadas, pesadas e aferiu-se a umidade. Realizou-se correção do peso da parcela para $13 \%$ de umidade e se calculou a produtividade em $\mathrm{kg} \mathrm{ha}^{-1}$. Para a avaliação da $\mathrm{MMG}$, foi realizada a contagem de 300 grãos, em seguida, extrapolou-se este valor para 1.000 grãos. A porcentagem de grãos ardidos foi obtida por meio da seleção manual dos grãos considerados ardidos de uma amostra de $250 \mathrm{~g}$ (Pinto, 2007). Após a seleção, estes foram pesados e se calculou a porcentagem de grãos ardidos.

Ainda da área útil da parcela, colheram-se dez espigas, sendo que cada espiga foi obtida de uma planta diferente. As espigas coletadas foram utilizadas para a avaliação dos componentes de rendimento (número de fileiras por espiga, número de grãos por fileira e número de grãos por espiga). O valor para estas variáveis foi obtido por meio da contagem direta de cada variável.

Para cada caráter avaliado, os dados foram analisados por meio de análise de variância e Teste F. Tendo sido detectada diferença significativa (com nível de significância de 0,05 ou 0,01 de probabilidade), pelo teste $\mathrm{F}$, as médias dos fatores qualitativos (safras) foram comparadas entre si pelo teste $t$, (a 0,05 de probabilidade) e as médias dos fatores quantitativos (doses de $\mathrm{N}$ complementar e densidade populacional) foram analisadas via análise de regressão pelo software Sisvar. Com os valores das equações obtidas na análise de regressão, calculou-se também o ponto de máxima eficiência técnica (MET) (quando a resposta foi quadrática) por meio das fórmulas: $\Delta=\boldsymbol{b}^{2}-4 . \boldsymbol{a} . \boldsymbol{c} ; v \boldsymbol{v}=-\boldsymbol{b} / \mathbf{2} \boldsymbol{a} ; \boldsymbol{y} \boldsymbol{x}=-\Delta / \mathbf{4} \boldsymbol{a}$. Por fim, quando foi detectada interação significativa entre fatores, foi realizado o desdobramento da ANAVA, para estudo da interação. Deste modo, foram analisados os níveis de um fator dentro dos níveis do outro fator, realizando teste de comparação de médias no caso de fatores qualitativos (safras dentro de níveis de densidade populacional) e de regressão, no caso de fatores quantitativos (densidade de população dentro de safras).

\section{Resultados e Discussão}

Observou-se que o efeito da fonte de variação devida ao tipo de população foi significativo $(p \leq 0,05)$ para todas as variáveis estudadas, exceto para porcentagem de grãos ardidos (Tabela 2). O efeito da fonte de variação devida ao $\mathrm{N}$ complementar foi altamente significativo apenas para a variável produtividade. Verificou-se ainda que todas as variáveis estudadas foram influenciadas, significativamente $(\mathrm{p} \leq 0,05)$, pelo efeito da fonte de variação de safras. Também observou-se interação significativa $(\mathrm{p} \leq 0,05)$ entre os fatores popu- 
lações e safras para as variáveis produtividade, MMG, grãos ardidos, número de fileiras por espiga e número de grãos por espiga. As demais interações duplas e a interação tripla não foram significativas ( $\mathrm{p}>0,05)$.

Houve diferença significativa entre as safras para todas as variáveis. Foram observados valores de maior magnitude na safra de 2014/15 para todas as variáveis estudadas (Tabela 3), o que é favorável no caso dos caracteres produtividade, massa de mil grãos, número de fileiras, número de grãos por fileira e por espiga e desfavorável para altura de planta, altura da inserção da primeira espiga e número de grãos ardidos. Essas diferenças, principalmente de produti- vidade, podem ser explicadas pela semeadura tardia realizada na safra 2015/16 quando comparada a safra 2014/15 (Tabela 1). As baixas temperaturas, inclusive com riscos de geadas, impossibilitaram a semeadura no mês de setembro, e optou-se por implantar o experimento no começo do mês de outubro. Além disso, na safra 2015/16 a temperatura média no período do florescimento (janeiro de 2016) estava mais elevada, o que favoreceu o aumento da incidência de doenças nessa safra. $\mathrm{O}$ atraso na semeadura, bem como a elevada pressão de doenças, contribuiu para que as produtividades obtidas na safra 2015/16 fossem menores quando comparadas com as obtidas na safra 2014/15.

Tabela 1. Informações das safras estudadas nos ensaios nas safras 2014/15 e 2015/16. Guarapuava-PR, 2018.

\begin{tabular}{ccc}
\hline Atividades & \multicolumn{2}{c}{ Safra } \\
\cline { 2 - 3 } Semeadura & $2014 / 15$ & $2015 / 16$ \\
Híbridos & $13 / 09 / 2014$ & $01 / 10 / 2015$ \\
Espaçamento & As 1656 PRO III & As 1656 PRO III \\
Adubação de base $\left(\mathrm{kg} \mathrm{ha}^{-1}\right)$ & $0,40 \mathrm{~m}$ & $0,40 \mathrm{~m}$ \\
$\mathrm{~N}$ & & 49,4 \\
$\mathrm{P}_{2} \mathrm{O}_{5}$ & 49,4 & 133 \\
$\mathrm{~K}_{2} \mathrm{O}$ & 133 & 38 \\
Adubação $N$ de cobertura & 38 & $18 / 10 / 2015$ \\
$\mathrm{~V} 2$ & & $01 / 11 / 2015$ \\
$\mathrm{~V} 4$ & $11 / 10 / 2014$ & \\
Aplicação do $N$ complementar & $24 / 10 / 2014$ & $23 / 12 / 2015$ \\
$\mathrm{VT}$ & & \\
\hline
\end{tabular}

Tabela 3. Produtividade, massa de mil grãos (MMG), grãos ardidos, altura de inserção da primeira espiga (Alt. Inserção), altura de planta (Alt. Planta), número de fileiras por espiga, grãos por fileira e grãos por espiga da cultura do milho em diferentes safras agrícolas. Guarapuava-PR, 2018.

\begin{tabular}{ccccccccc}
\hline Safra & Produtividade & MMG & Alt. Inserção & Alt. Planta & Ardido & Fileiras & Grãos/Fileira & Grãos/Espiga \\
\hline $2014 / 15$ & $15696 \mathrm{a}$ & $356,74 \mathrm{a}$ & $116,59 \mathrm{a}$ & $256,30 \mathrm{a}$ & $8,06 \mathrm{a}$ & $19,06 \mathrm{a}$ & $36,40 \mathrm{a}$ & $685,46 \mathrm{a}$ \\
$2015 / 16$ & $11222 \mathrm{~b}$ & $294,36 \mathrm{~b}$ & $111,90 \mathrm{~b}$ & $241,25 \mathrm{~b}$ & $6,06 \mathrm{~b}$ & $18,81 \mathrm{~b}$ & $32,39 \mathrm{~b}$ & $618,70 \mathrm{~b}$ \\
\hline
\end{tabular}

Médias seguidas das mesmas letras não diferem entre si pelo teste $t$. 
Conforme mencionado por Santos et al. (2013a) é de fundamental importância considerar as condições edafoclimáticas de cada safra agrícola, por causa dos efeitos de cada ano, pois os efeitos de safra interferem diretamente na produtividade da cultura. A ausência de interação entre N complementar x Safra permite inferir que o aumento de produtividade obtido por meio da aplicação de até $10 \mathrm{~L} \mathrm{ha}^{-1}$ de $\mathrm{N}$ complementar não está condicionado a certas safras e demonstra a estabilidade das respostas. Além disso, não foi verificada interação entre $\mathrm{N}$ complementar $\mathrm{x}$ população de plantas, o que sugere que mesmo nas mais distintas populações de plantas a produtividade respondeu de maneira positiva ao uso do $\mathrm{N}$ complementar.

A variável produtividade respondeu às diferentes populações de plantas de maneira linear para a safra 2014/15 e quadrática para a safra 2015/16 (Figura 2A). Verificou-se ainda que houve diferença entre as safras, sendo que independentemente da população de plantas utilizada, a produtividade da safra 2014/15 foi superior à verificada na safra 2015/16, como mencionado anteriormente (Tabela 2). A resposta quadrática da produtividade está relacionada com o grau de competição intraespecífica. Assim, quando há uma competição elevada entre plantas a tendência é que ocorra diminuição de produtividade (Vitorazzi et al., 2017). Resultados análogos foram verificados por Farinelli e Cerveira Júnior (2014), sendo que, de acordo com tais autores, houve acréscimos de produtividade com o aumento da população de plantas até 80.000 plantas ha ${ }^{-1}$. O aumento de produtividade em função do aumento da população de plantas deve-se ao crescimento do número de espigas por área. Embora verificada diminuição da produção por planta, verificou-se aumento da produção por área.

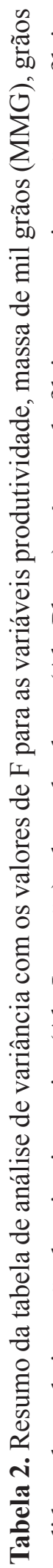

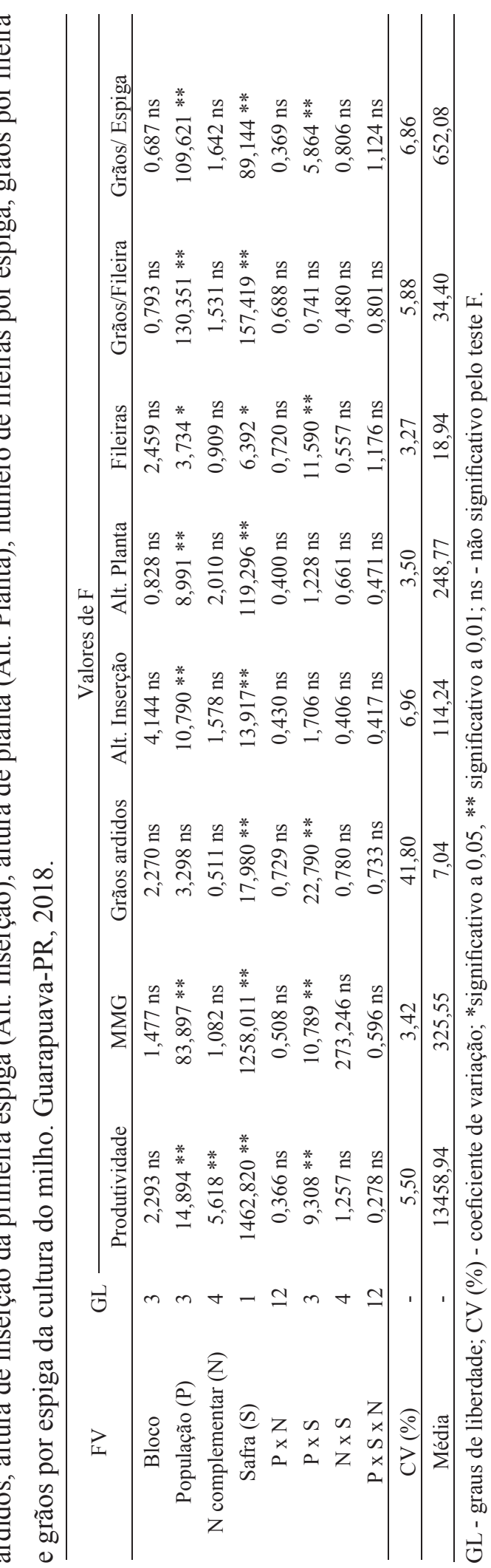


Na média das safras, a produtividade respondeu de maneira quadrática ao uso do $\mathrm{N}$ complementar. A produtividade de máxima eficiência técnica $(13.783$ $\mathrm{kg} \mathrm{ha}^{-1}$ ) foi obtida por meio da aplicação de $10,60 \mathrm{~L}$ ha $^{-1}$ de $\mathrm{N}$ complementar. A aplicação dessa dose proporcionou incremento de produtividade de $722 \mathrm{~kg}$ ha-1, quando comparado com a não aplicação de $\mathrm{N}$ complementar. A produtividade da cultura do milho é diretamente influenciada pelo fornecimento de $\mathrm{N}$, pois este nutriente exerce funções importantes no metabolismo vegetal, já que influencia na formação dos aminoácidos que constituem as proteínas, além de estar associado diretamente ao crescimento de plantas por participar na molécula de clorofila, indispensável para a manutenção da atividade fotossintética (Basi et al., 2011). Em função dos incrementos na produtividade da cultura do milho obtidos neste trabalho, verificou-se que a aplicação de $\mathrm{N}$ via foliar no milho pode ser uma maneira eficiente para complementar o que é absorvido pelas raízes. A importância da aplicação de $\mathrm{N}$ complementar na cultura do milho para a obtenção de altas produtividades já foi discutida anteriormente por (Pacentchuk et al., 2018).

Conforme a Figura 3A, o aumento da população de plantas proporcionou redução na $\mathrm{MMG}$. Para todas as populações de plantas estudadas, os maiores valores de MMG foram verificados na safra 2014/15 em comparação com a safra 2015/16. Com o aumento da população de plantas, tem-se maior competição por fatores como luz e nutrientes entre as plantas. Nessas condições, as plantas produzem espigas menores, grãos menores, e consequentemente menores massas de grãos (Vitorazzi et al., 2017). Os achados deste trabalho corroboram com os achados de Rossato Júnior et al. (2013), que observaram redução da MMG com o aumento da população de plantas.
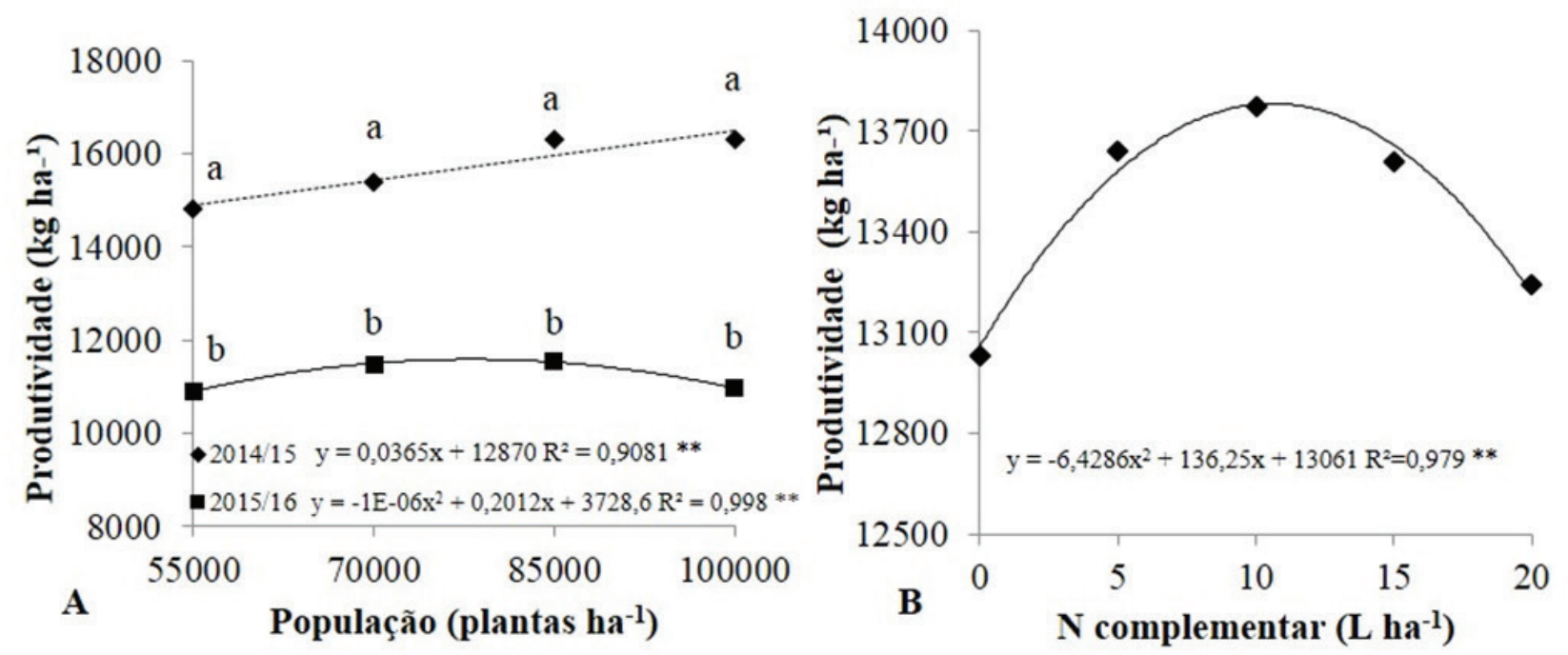

Figura 2. Produtividade da cultura do milho em $\mathrm{kg} \mathrm{ha}^{-1} \mathrm{em}$ função de diferentes populações de plantas na safra 2014/15 (४) e 2015/16 (•) (A) e de doses crescentes de N complementar (B). Guarapuava-PR, 2018.

** - significativo $(\mathrm{p} \leq 0,01)$ pela análise de regressão. Médias de produtividade, por safra, seguidas pela mesma letra não diferem entre si pelo teste t. 
O aumento da população de plantas proporcionou resultados distintos entre as safras estudadas para porcentagem de grãos ardidos. Na safra 2014/15, o aumento da população de plantas ocasionou diminuição na porcentagem de grãos ardidos, enquanto que na safra 2015/16 o crescimento da população de plantas proporcionou aumento na porcentagem de grãos ardidos (Figura 3B), caracterizando interação do tipo complexa entre tamanho das populações e safras para o caráter em questão, diferentemente do que ocorreu no caso dos caracteres produtividade de grãos e MMG, para os quais essa interação, embora significativa (Tabela 2), foi do tipo simples. Segundo Casa et al. (2007), a maior densidade populacional pode levar à predisposição da planta ao ataque de patógenos.

O aumento da população de plantas proporcionou aumento na altura de inserção da primeira espiga e também na altura de planta (Figuras 4A e 4B, respectivamente). Segundo Brachtvogel et al. (2012), a resposta está relacionada ao efeito da competição intraespecífica por luz, com consequente estímulo da dominância apical das plantas. Os achados deste trabalho estão em concordância com os resultados encontrados por Pinho et al. (2009), que, quando avaliaram híbridos de milho em diferentes populações, verificaram que menores alturas de plantas e de inserção de espiga ocorreram nas menores densidades de plantas.

Verificou-se que o aumento da população de plantas, na média das safras, proporcionou diminuição no número de grãos por fileira (Figura 5A) e também redução no número de fileiras por espiga. $\mathrm{Na}$ densidade populacional de 55.000 plantas ha-1, o número de fileiras por espiga verificado na safra 2014/15 foi inferior ao observado na safra 2015/16 (Figura 5B). Como consequência especialmente da diminuição do número de fileiras por espiga e de grãos por fileira em função do aumento da população de plantas, verificou-se, em ambas as safras, redução no número de grãos por espiga (Figura $5 \mathrm{C}$ ). Na população de 55.000 plantas ha-1 não houve diferença entre as safras para o número de grãos por espiga. No entanto, para as demais populações, o número de grãos por espiga encontrados na safra 2014/15 foi superior ao verificado na safra 2015/16.

Os dados deste trabalho corroboram com os achados de Vieira et al. (2010) e Brachtvogel et al. (2012), autores que verificaram que os componentes de rendimento, número de grãos por fileira e grãos por espiga foram influenciados negativamente pelo aumento da população de plantas. Com o aumento da população de plantas, há redução no tamanho das espigas, diminuindo também seu índice por planta. Entretanto, há compensação na produção, pelo aumento do número de plantas por área (Dourado Neto et al., 2003). Mesmo com menor produção por planta, o maior número de espigas produzidas por área em decorrência do aumento da população de plantas proporcionou aumento na produtividade da cultura (Figura 2A).

Nossos achados sugerem que, nas condições em que o estudo foi conduzido, a aplicação de N complementar via foliar se mostra como uma importante alternativa para aumentar a produtividade da cultura do milho. É necessário destacar que, para o genótipo estudado, a dose de $\mathrm{N}$ complementar que apresenta o melhor resultado técnico não sofre alterações em função do aumento da densidade populacional. Entretanto, novos estudos devem ser conduzidos em diferentes condições edafoclimáticas e com diferentes genótipos, para gerar novos resultados que auxiliarão na melhor compreensão do emprego desta técnica e, consequentemente, favorecerá o aumento de produtividade da cultura do milho. 


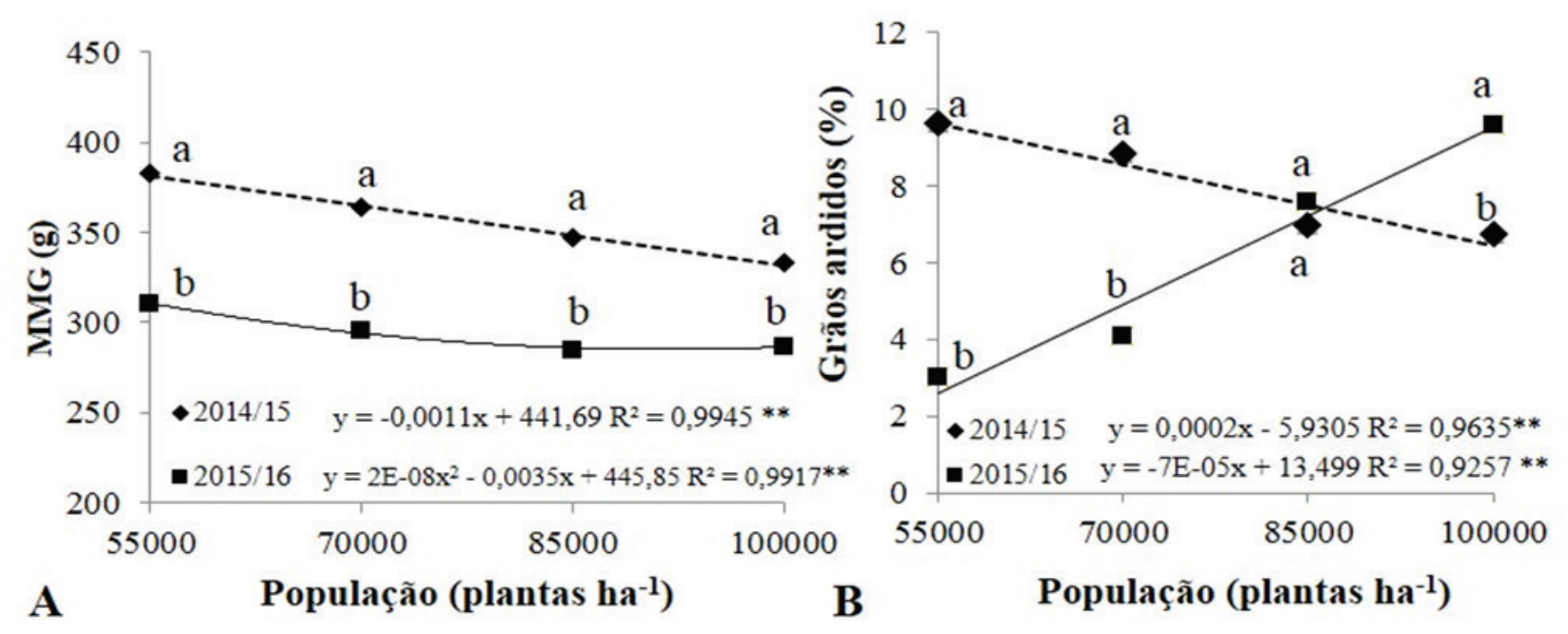

Figura 3. Massa de mil grãos (MMG - g) (A) e porcentagem de grãos ardidos (\%) (B) da cultura do milho em função de diferentes populações de plantas na safra 2014/15 (») e 2015/16 (ロ). Guarapuava, PR - 2018. ** - significativo a $1 \%$ pela análise de regressão. Médias seguidas pela mesma letra não diferem entre si pelo teste $t$.

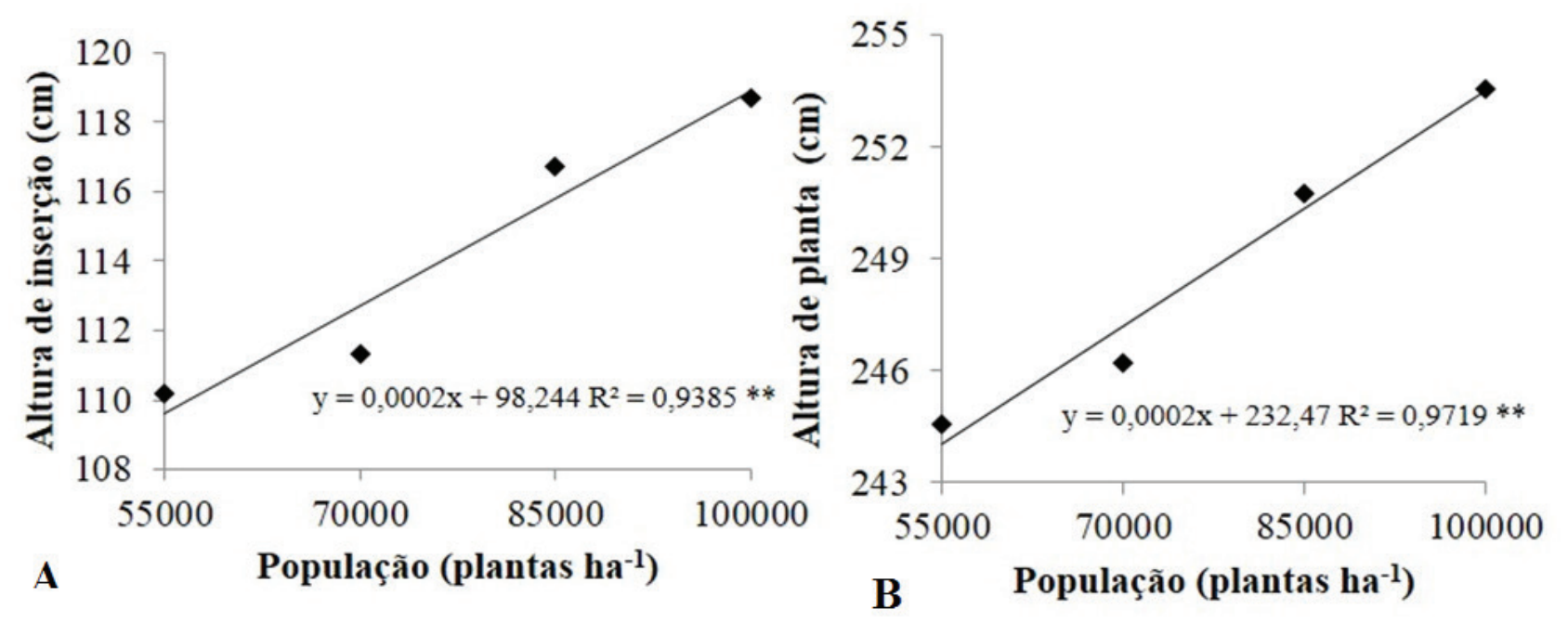

Figura 4. Altura de inserção da primeira espiga $(\mathrm{cm})(\mathrm{A})$ e altura de planta $(\mathrm{cm})(\mathrm{B})$ da cultura do milho em função de diferentes populações de plantas na média das safras. Guarapuava-PR, 2018.

** - significativo $(\mathrm{p} \leq 0,01)$ pela análise de regressão. 


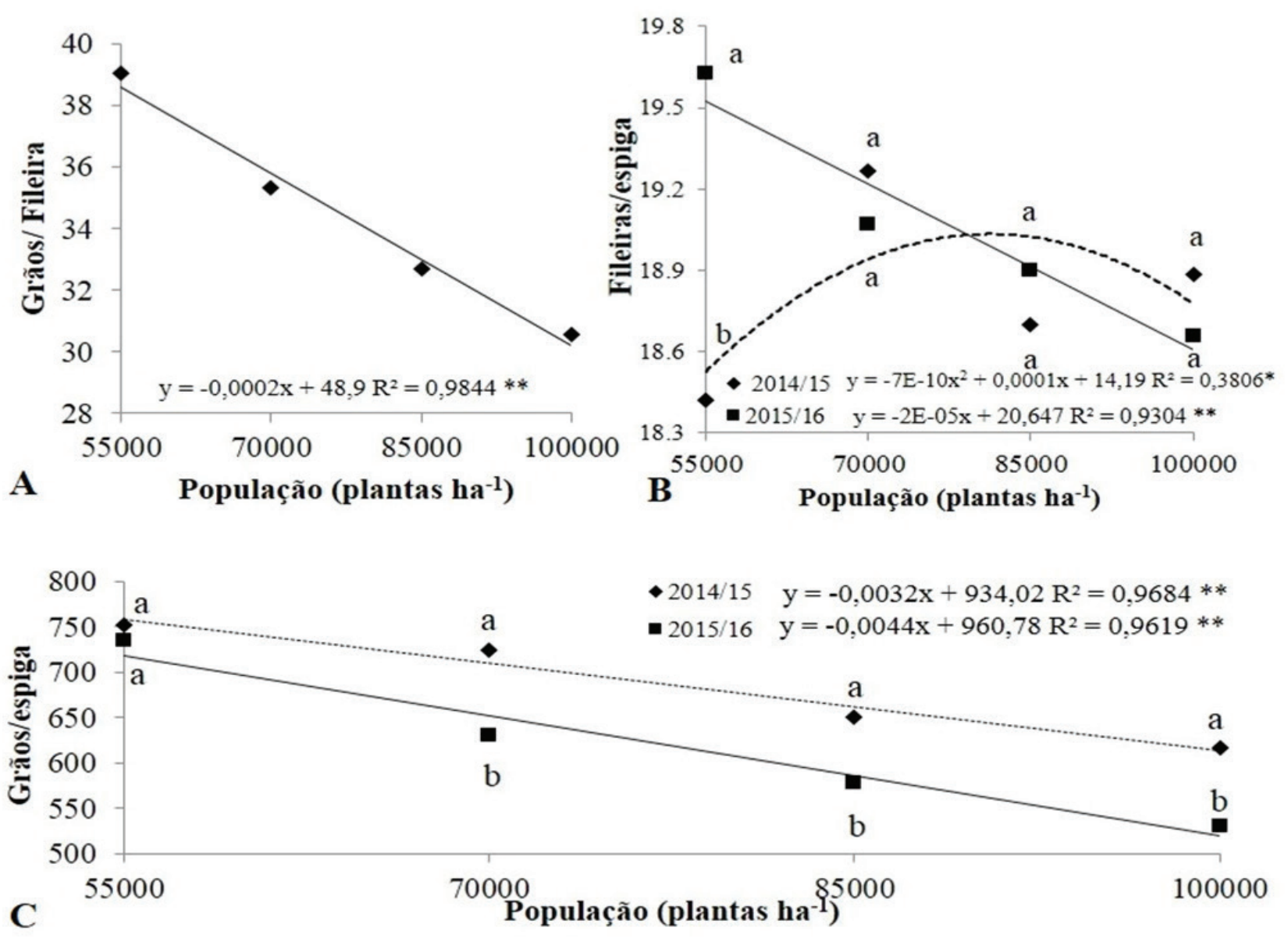

Figura 5. Número de grãos por fileira na média das safras (A), número de fileiras por espiga na safra 2014/15

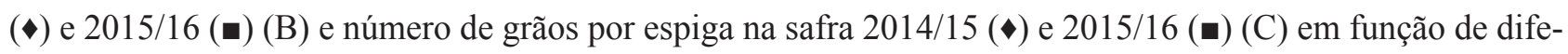
rentes populações de plantas. Guarapuava-PR, 2018.

** - significativo a $(\mathrm{p} \leq 0,01)$ pela análise de regressão. Médias seguidas pela mesma letra não diferem entre si pelo teste $t$.

\section{Conclusões}

Nas condições de estudo, não houve interação entre população de plantas e $\mathrm{N}$ complementar para nenhuma das variáveis estudadas.

A aplicação de $\mathrm{N}$ complementar proporcionou acréscimo de produtividade na cultura do milho. A dose de máxima eficiência técnica, 10,60 L ha ${ }^{-1}$ de N complementar, proporcionou o incremento de produtividade de $722 \mathrm{~kg} \mathrm{ha}^{-1}$, os demais caracteres não foram afetados.
Em função do aumento da população de plantas, houve aumento linear e quadrático de produtividade, para as safras 2014/15 e 2015/16 respectivamente.

O aumento da densidade populacional diminuiu a massa de mil grãos, número de fileiras por espiga, grãos por fileira e grãos por espiga. Nessas condições, verificou-se ainda aumento na altura de inserção da primeira espiga e na altura de planta. 


\section{Referências}

BASI, S.; NEUMANN, M.; MARAFON, F.; UENO, R. K.; SANDINI, I. E. Influência da adubação nitrogenada sobre a qualidade da silagem de milho. Revista Brasileira de Tecnologia Aplicada nas Ciências Agrárias, v. 4, n. 3 , p. 219-234, 2011.

BRACHTVOGEL, E. L.; PEREIRA, F. R. D. S.; CRUZ, S. C. S.; ABREU, M. L. D. BICUDO, S. J. População, arranjo de plantas uniforme e a competição intraespecífica em milho. Revista Trópica - Ciências Agrárias e Biológicas, v. 6, n. 1, p. 75-83, 2012.

CANCELLIER, L. L.; AFFÉRRI, F. S.; CARVALHO, E. V. D.; DOTTO, M. A. LEÃO, F. F. Eficiência fenotípica em populações tropicais de milho no Tocantins. Revista Ciência Agronômica, v. 42, n. 1, p. 139-148, 2011.

DOI: $10.1590 / \mathrm{S} 1806-66902011000100018$.

CASA, R. T.; MOREIRA, E. N.; BOGO, A.; SANGOI, L. Incidência de podridões do colmo, grãos ardidos e rendimento de grãos em híbridos de milho submetidos ao aumento na densidade de plantas. Summa Phytopathologica, v. 33, n. 4, p. 353-357, 2007.

DOI: $10.1590 / \mathrm{S} 0100-54052007000400006$.

CHAGAS, J. F. R.; SANTOS, G. R. D.; COSTA, R. V. D.; ALVES, J. F.; NASCIMENTO, I. R. D. Adubação nitrogenada na severidade de doenças foliares, produtividade e respostas bioquímicas em híbridos de milho. Revista Brasileira de Milho e Sorgo, v. 17, n. 1, p. 1-14, 2018.

DOI: 10.18512/1980-6477/rbms.v17n1p1-14.

DOURADO NETO, D.; PALHARES, M.; VIEIRA, P. A.; MANFRON, P. A.; MEDEIROS, S. L. P.; ROMANO, M. R. Efeito da população de plantas e do espaçamento sobre a produtividade de milho. Revista Brasileira de Milho e Sorgo, v. 2, n. 3, p. 63-77, 2003.

DOI: 10.18512/1980-6477/rbms.v2n3p63-77.

FARINELLI, R.; CERVEIRA JÚNIOR, W. R. Resposta de cultivares de milho transgênico e convencional a densidades populacionais. Revista Brasileira de Milho e

Sorgo, v. 13, n. 3, p. 336-346, 2014.

DOI: 10.18512/1980-6477/rbms.v13n3p336-346.

FOLADOR, L. G.; ASSMANN, E. J.; AGUIAR, C. G. Nitrogênio em cobertura em diferentes densidades de milho de segunda safra. Revista Cultivando o Saber, v. 7, n. 3, p. 242-253, 2014.

FRAZÃO, J. J.; SILVA, A. R. da; SILVA, V. L. da; OLIVEIRA, V. A.; CORREA, R. S. Fertilizantes nitrogenados de eficiência aumentada e ureia na cultura do milho. Revista Brasileira de Engenharia Agrícola e Ambiental, v. 18, n. 12, p. 1262-1267, 2014.

DOI: 10.1590/1807-1929/agriambi.v18n12p1262-1267.

KAPPES, C.; ANDRADE, J.A.D. C.; ARF, O.; OLIVEIRA, Â. C. D.; ARF, M. V.; FERREIRA, J. P. Arranjo de plantas para diferentes híbridos de milho. Pesquisa Agropecuária Tropical, v. 41, n. 3, p. 348-359, 2011.

LANA, M. D. C.; RAMPIM, L.; OHLAND, T.; FÁVERO, F. Espaçamento, densidade populacional e adubação nitrogenada na cultura do milho. Revista Ceres, v. 61, n. 3, p. 424-433, 2014.

MAAK, R. Geografia física do estado do Paraná. Curitiba: Banco do Desenvolvimento do Paraná, 1968. 350 p.

NOVAKOWISKI, J. H.; SANDINI, I. E.; FALBO, M. K.; MORAES, A. D.; NOVAKOWISKI, J. H.; CHENG, N. C. Efeito residual da adubação nitrogenada e inoculação de Azospirillum brasilense na cultura do milho. Semina: Ciências Agrárias, v. 32, p. 16871698, 2011. Suplemento 1.

PACENTCHUK, F.; NOVAKOWISKI, J. H.; SANDINI, I. E. Complementary nitrogen fertilization and foliar fungicide on maize in southern Brazil. In: PEREZ RODRÍGUEZ, P. (Ed.). Fungicides perspectives, resistance management and risk assessment. New York: Nova Science Publishers, 2018.

PINHO, R. G. V.; RIVERA, A. A. C.; BRITO, A. H. D.; LIMA, T. G. D. Avaliação agronômica do cultivo de 
milho em diferentes níveis de investimento. Ciência e Agrotecnologia, v. 33, n. 1, p. 39-46, 2009.

DOI: $10.1590 /$ S1413-70542009000100005.

PINTO, N. F. J. de A. Reação de cultivares com relação à produção de grãos ardidos em milho. Sete Lagoas: Embrapa Milho e Sorgo, 2007. 4 p. (Embrapa Milho e Sorgo. Comunicado Técnico, 144).

PRIMAZ, E.; BALESTRIN, A. L.; CONTE, C. S.; JUNGES, R. C.; CAMILO, M.; TREVIZAN, K. Doses de nitrogênio e população de plantas na cultivar de milho DKB 240 PRO. RAMVI - Revista de Agronomia e Medicina Veterinária IDEAU, v. 2, n. 3, p. 1-12, 2015.

ROSSATO JÚNIOR, J. A. D. S.; CAZETTA, D. A.; BARBOSA, J. C. FORNASIERI FILHO, D. Popping expansion and yield responses of popcorn cultivars under different row spacings and plant populations. Pesquisa Agropecuária Brasileira, v. 48, n. 12, p. 1538-1545, 2013. DOI: 10.1590/S0100-204X2013001200002.

SANTOS, G. R. D.; GAMA, F. R.; GONÇALVES, C. G.; RODRIGUES, A. C.; LEÃO, E. U.; CARDON, C. H. BONIFACIO, A. Severidade de doenças foliares e produtividade de genótipos de milho em resposta à adubação nitrogenada. Revista Ceres, v. 60, n. 4, p. 505513, 2013a. DOI: 10.1590/S0034-737X2013000400009.
SANTOS, H. G. dos; JACOMINE, P. K. T.; ANJOS, L. H. C. dos; OLIVEIRA, V. A. de; LUMBRERAS, J. F.; COELHO, M. R.; ALMEIDA, J. A. de; CUNHA, T. J. F.; OLIVEIRA, J. B. de. Sistema brasileiro de classificação de solos. 3. ed. rev. e ampl. Brasília, DF: Embrapa, 2013 b. $353 \mathrm{p}$.

TAIZ, L.; ZEIGER, E.; MOLLER, I. M. MURPHY, A. Fisiologia e desenvolvimento vegetal. 6 . ed. Porto Alegre: Artmed, 2017. 888 p.

TAKASU, A. T.; RODRIGUES, R. A. F.; GOES, R. J.; ARF, O. HAGA, K. I. Desempenho agronômico do milho sob diferentes arranjos populacionais e espaçamento entrelinhas. Revista Agrarian, v. 7, n. 23, p. 34-41, 2014.

VIEIRA, M. D. A.; CAMARGO, M. K.; DAROS, E.; ZAGONEL, J. KOEHLER, H. S. Cultivares de milho e população de plantas que afetam a produtividade de espigas verdes. Acta Scientiarum. Agronomy, v. 32, n. 1, p.81-86, 2010.

VITORAZZI, C.; AMARAL JÚNIOR, A. T.; CANDIDO, L. S.; FREITAS, I. L. D. E. J. SILVA, T. R. D. A. C. Arranjo populacional para a variedade Uenf-14 de milho pipoca. Revista Brasileira de Milho e Sorgo, v. 16, n. 3, p. 401, 2017.

DOI: 10.18512/1980-6477/rbms.v16n3p401-413. 